\title{
Incorporating Entrepreneurially Minded Learning into a Junior/Senior Level Mechatronics Course Project Covering Dynamic Systems, Modeling, and Con- trol
}

\section{Dr. James A. Mynderse, Lawrence Technological University}

James A. Mynderse, $\mathrm{PhD}$ is an Assistant Professor in the A. Leon Linton Department of Mechanical Engineering at Lawrence Technological University. His research interests include mechatronics, dynamic systems, and control with applications to piezoelectric actuators, hysteresis, and perception. He serves as the faculty advisor for the LTU Baja SAE team. 


\title{
Incorporating Entrepreneurially Minded Learning into a Junior/Senior Level Mechatronics Course Project Covering Dynamic Systems, Modeling, and Control
}

\begin{abstract}
At Lawrence Technology University, a junior/senior level mechatronics course within the undergraduate mechanical engineering program was modified to include entrepreneurially minded learning content in existing problem-based learning activities. The real-world projects incorporated modeling and analysis of dynamic systems, selection and integration of sensors and actuators, and feedback control. This study assessed the course modifications based on student behaviors corresponding to an entrepreneurial mindset. The entrepreneurial mindset was defined by the KEEN framework including the "three Cs" and associated example behaviors. Course modifications included a fictitious customer created to provide direct student-customer interaction throughout the process. Other elements were added in project stages to focus student attention on economic drivers. Student surveys indicated that the students demonstrated the tested entrepreneurial mindset example behaviors at least "sometimes" and up to "often". Further work is needed to test all example behaviors within the KEEN entrepreneurial mindset framework.
\end{abstract}

\section{Introduction}

At Lawrence Technological University (Lawrence Tech), faculty are engaged in a multiyear process to incorporate active and collaborative learning (ACL), problem-based learning (PBL), and entrepreneurially minded learning (EML) into the engineering curriculum $[1,2,3]$. Active learning requires students to actively discuss issues or work problems in the classroom, rather than listening passively to a lecture. If students informally assist one another in this process, the technique is deemed collaborative learning [4]. A related approach, problem-based learning, introduces engaging real-world problems for students to solve, usually as part of a group [5]. A new twist on problem-based learning is the inclusion of student skills associated with an entrepreneurial mindset, such as integrating information from many sources to gain insight, conveying engineering solutions in economic terms, and identifying unexpected opportunities. The resulting entrepreneurially minded learning activities emphasize "discovery, opportunity identification, and value creation with attention given to effectual thinking over causal (predictive) thinking" [6]. Approximately $75 \%$ of the engineering curriculum, including mathematics and general education, is being modified to include ACL and PBL. These courses span the curriculum and range from multidisciplinary Introduction to Engineering [7, 8] to junior level technical courses $[9,10]$ to graduate level mechatronic design $[11,12]$.

As a member school in the Kern Entrepreneurial Engineering Network (KEEN), Lawrence Tech defines the entrepreneurial mindset in terms of the KEEN framework. The KEEN framework begins with the "three Cs": Curiosity, Connections, and Creating Value [13]. Each of the three Cs is supported by example student behaviors. For instance, Curiosity is demonstrated by "explore a contrarian view of accepted solutions" and Creating Value is demonstrated by "identify unexpected opportunities to create extraordinary value". The framework continues from the three 
Cs to Engineering Thought and Action, Collaboration, Communication, and Character. As with the three Cs, each concept is supported by example student behaviors. It is important to note that the entrepreneurial mindset is different from entrepreneurship. Rather than creating new ventures, the entrepreneurial mindset focuses on inclusion of entrepreneurial skills in engineering practice.

The junior/senior-level mechatronics course under consideration in this work serves undergraduate mechanical engineering students and introduces modeling and analysis of dynamic systems, integration of mechatronic systems, and feedback control of dynamic systems. Previous work on this course focused on the creation of real-world PBL modules based on known issues in a previous student capstone design project $[9,10]$. Following semesters continued the use of PBL modules, but without specific stakeholders or focus on the costs associated with student designs. In this work, the mechatronics course is modified to improve existing PBL modules by incorporating EML content. Based on student feedback, indirect assessment, and direct assessment, modifications were made to improve customer engagement and focus on conveying engineering solutions in economic terms.

This paper is organized as follows. First, mechatronics is defined and inclusion within the BSME curriculum at Lawrence Tech is introduced. Next, the existing course with PBL modules and the course modifications corresponding to the EML conversion are described. Finally, the EML components are evaluated through survey results and the work is concluded.

\section{Mechatronics in the BSME Program}

Mechatronics is characterized by an integration of mechanical, electronic, control, and computer systems and may be viewed as the intersection of these systems as shown in Figure 1. Mechanical systems may include thermal or fluid systems, solid mechanics, dynamics and vibrations. Electronic systems may include sensors, actuators, power systems, and communication systems. Control methodologies including both supervisory and part-level feedback control may be used to direct actions. Computer systems may include both the use of computers in the design phase and the integration of microprocessors into the final product. The study of mechatronics is, by nature, interdisciplinary.

The course under consideration, EME 3214 - Mechatronics, serves as a junior/senior-level required course for students enrolled in the BS Mechanical Engineering program as well as a pre-core course for students enrolled in the MS Mechatronic Systems Engineering program. Prerequisites include Dynamics, Circuits and Electronics, and Engineering Numerical Methods, as shown in Figure 2. No required courses feature Mechatronics as a prerequisite, though some technical electives do. While cataloged as a 3000 level course, the majority of students are seniors with juniors and new graduate students making up the balance. 


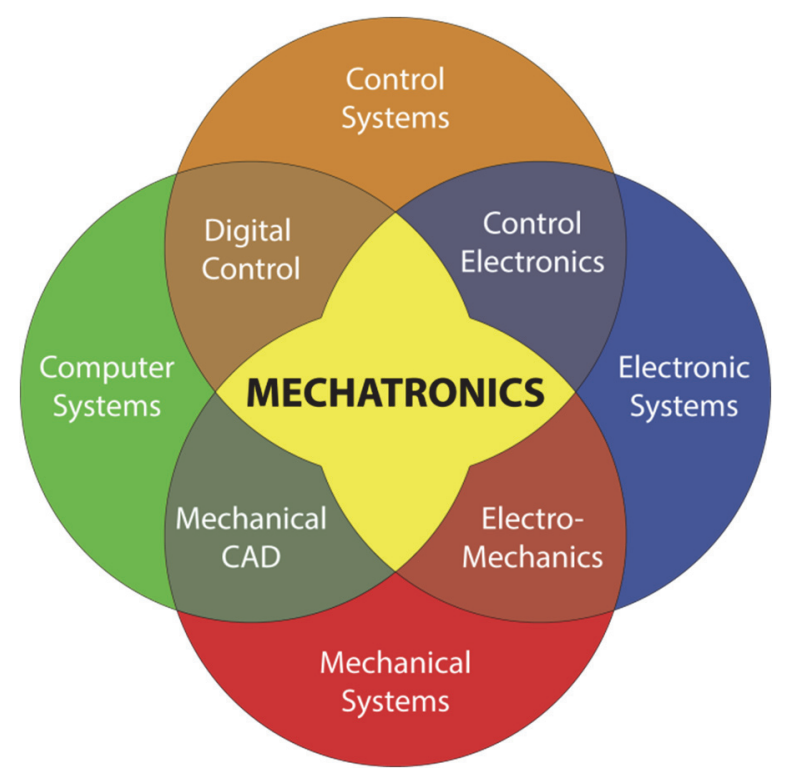

Figure 1. The interdisciplinary nature of Mechatronics [14].

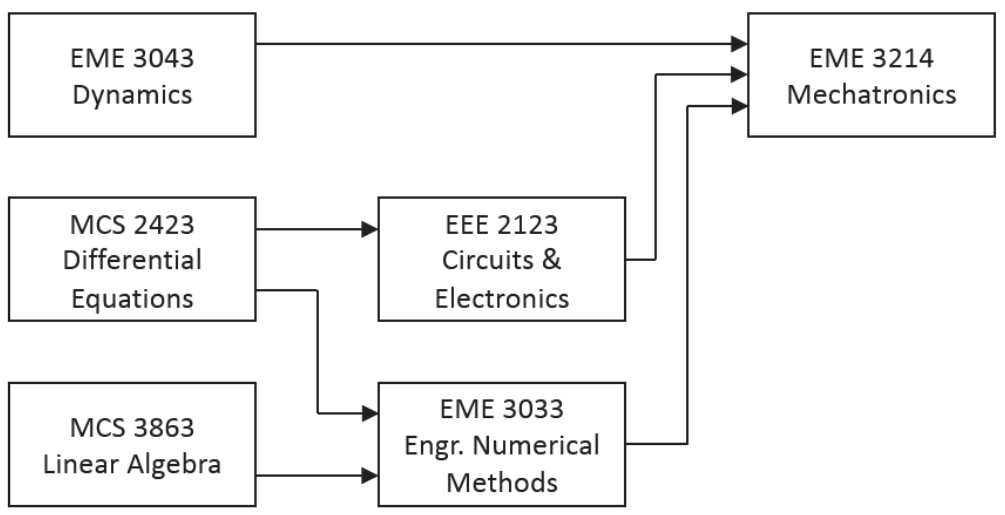

Figure 2. EME 3214 - Mechatronics with prerequisite courses.

The four-credit course is taught with three hours of lecture and two hours of laboratory. Because the lecture and laboratory sessions are considered a single section, class size is capped at 16 students per section to accommodate the available laboratory stations. Both daytime and evening sections are offered to accommodate a mix of traditional and working students. Adjunct faculty teach evening sections while full-time faculty and staff teach daytime sections. The class is offered in both Fall and Spring semesters, but only Fall 2015 and Fall 2016 courses are considered in the present study based on the author's teaching commitments. The breakdown of course offerings is shown in Table 1. 
Table 1. Breakdown of course sections considered in this work.

\begin{tabular}{|c|l|l|c|}
\hline Semester & \multicolumn{1}{|c|}{ Instructor } & Timeslot & Enrollment \\
\hline \multirow{2}{*}{ Fall 2015} & Full-Time Faculty & Daytime & 10 \\
\cline { 2 - 4 } & Adjunct Faculty & Evening & 13 \\
\hline \multirow{3}{*}{ Fall 2016} & Full-Time Staff & Daytime & 15 \\
\cline { 2 - 4 } & Full-Time Faculty & Daytime & 15 \\
\cline { 2 - 4 } & Adjunct Faculty & Evening & 15 \\
\hline
\end{tabular}

The course content covers four topics: modeling of dynamic systems, analysis of dynamic systems, integrating mechatronic systems, and feedback control systems. A list of detailed learning objectives for the overall course and individual modules are provided to students. The prerequisite Circuits and Electronics course did not include a laboratory prior to Fall 2016. Therefore, in addition to the planned learning objectives, Mechatronics serves as a first hands-on experience with electronics for many students. As an example, the overall course-wide learning objectives are given below. The numbers in parenthesis identify the associated revised Bloom's taxonomy [15] levels to ensure that learning objectives are of varying classifications.

At the end of this course, students should be able to:

- (2) Explain the importance of Mechatronics in relation to modern society.

- (6) Create analytical models for mechanical, electrical, and hydraulic systems.

- (4) Analyze the stability, step response, and frequency response of a system using MATLAB.

- (3) Select appropriate sensors for a system based on specifications.

- (6) Design a PID controller for a particular system and set of performance specifications.

- (5) Validate that the closed-loop system meets the performance specifications using MATLAB.

The course organization was structured around the four topic areas, as shown in the Fall 2016 course schedule provided in Figure 3. The first four weeks covered modeling of dynamic systems (yellow), then four weeks were devoted to analysis of dynamic systems (orange), before four weeks on integrating mechatronic systems (blue), and three weeks on feedback control (green).

\begin{tabular}{|c|c|c|c|c|c|c|c|}
\hline \multicolumn{2}{|c|}{ Week } & Reading & Class Period 1 & Reading & Class Period 2 & Videos & Lab Period \\
\hline 1 & $08 / 22 / 16$ & Ch. 1 & Administration / Introduction & Ch. 2 & Modeling Systems & MATLAB & Fun with Circuits \\
\hline 2 & $08 / 29 / 16$ & Ch. 2,3 & Mechanical Systems & Ch. 4 & Electrical and Hydraulic Systems & Block Diagrams / State Space & Electromagnet/ Paint Sprayer \\
\hline 3 & $09 / 05 / 16$ & & Labor Day & Ch. 5 & Transfer Functions & Circuit Analysis, Laplace Transforms & Arduino, Transistors, Switches \\
\hline 4 & $09 / 12 / 16$ & & Transfer Functions / Stability & & Case Study: Segway / PBL 1 & & PBL 1 \\
\hline 5 & $09 / 19 / 16$ & Ch. 5 & Time Response & Ch. 5 & Time Response / Review & & Time Response $(\mathrm{H}, \mathrm{P}, \mathrm{T})$ \\
\hline 6 & $09 / 26 / 16$ & & Exam 1 & Ch. 7 & Frequency Response & & Time Response $(\mathrm{H}, \mathrm{P}, \mathrm{T})$ \\
\hline 7 & $10 / 03 / 16$ & Ch. 7 & Frequency Response & Ch. 7 & Frequency Response & Fourier Series & Frequency Response (circuit) \\
\hline 8 & $10 / 10 / 16$ & & System Identification & & PBL 1 & Bode Plots & PBL 1 \\
\hline 9 & $10 / 17 / 16$ & & Intregrating Systems & & Sensor Calibration & Diodes / Transistors / OpAmps & Sensor Calibration (H, P, IR) \\
\hline 10 & $10 / 24 / 16$ & & Sensor Calibration & & $\mathrm{A} / \mathrm{D}$ and $\mathrm{D} / \mathrm{A}$ & Pos. and Vel. Sensors & Sensor Calibration $(\mathrm{H}, \mathrm{P}, \mathrm{IR})$ \\
\hline 11 & $10 / 31 / 16$ & & $\mathrm{~A} / \mathrm{D}$ and $\mathrm{D} / \mathrm{A}$ & & Review & & Active Filters \\
\hline 12 & $11 / 07 / 16$ & & Exam 2 & & Misc. Sensors / Actuators & DC Motor / Stepper Motor & DC Motor \\
\hline 13 & $11 / 14 / 16$ & & PBL 2 & & Feedback Control & & PBL 2 \\
\hline 14 & $11 / 21 / 16$ & & Feedback Control & & Thanksgiving & Thanksgiving & Thanksgiving \\
\hline 15 & $11 / 28 / 16$ & Ch. 8 & PID Control & Ch. 8 & PID Control & & PBL 3 \\
\hline 16 & $12 / 05 / 16$ & Ch. 6 & Root Locus Design & & Review & & PBL 3 \\
\hline
\end{tabular}

Figure 3. Fall 2016 course schedule color-coded by topic area. 


\section{ACL, PBL and EML Implementation}

Previous course development efforts incorporated ACL techniques to counter student misconceptions about course material being unrelated to "traditional" mechanical engineering while improving student learning. During AY 2012-2013 and 2013-2014, the author collected anecdotal evidence that students did not see the relevance of mechatronics to their lives or society. During Summer 2014, the author participated in the KIT5 cohort for internal training on ACL at Lawrence Tech [2] and created ACL modules specifically targeting applications of mechatronics. The more successful module, dubbed "Mechatronic Systems in the Wild" consists of a variety of slides for inclusion at the beginning of each lecture. Each slide shows pictures of a particular system and asks "Is this a mechatronic system?" Students participate in a Think-Pair-Share [16] in which the correct answer is always "yes", but the discussion centers on the elements of mechatronics as they are represented in the demonstrated system. Examples of "Mechatronic Systems in the Wild" slides are shown in Figure 4.

IS THIS A MECHATRONIC SYSTEM?

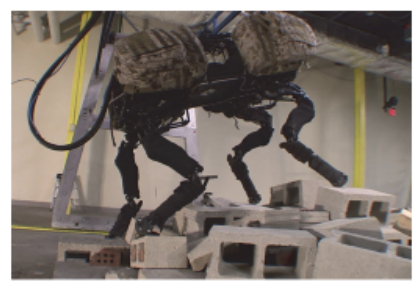

A. Yes

B. No

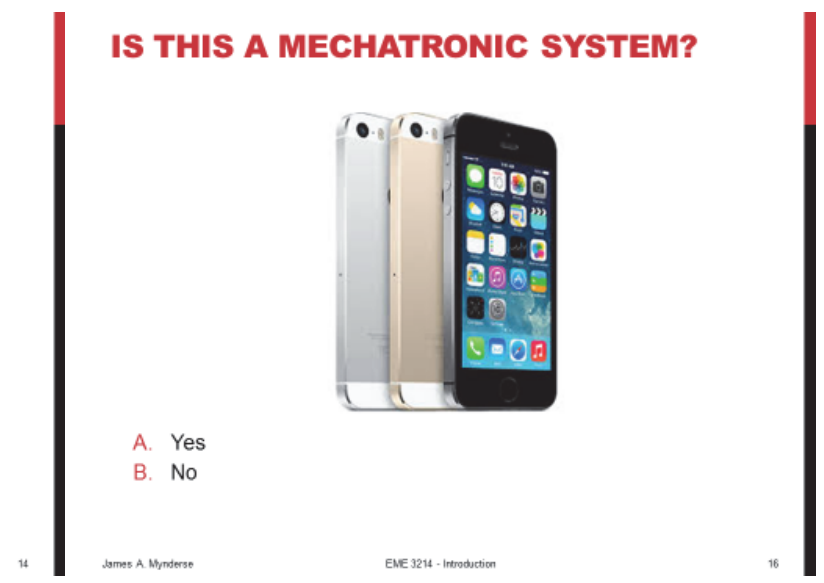

Figure 4. Sample Think-Pair-Share slides from the "Mechatronic Systems in the Wild" module.

In addition to the easy implementation of Think-Pair-Shares, larger-scale real-world PBL modules were introduced, starting in Fall 2013. Initial PBL modules were distinct problems focusing on one of the four topic areas for the course: modeling, analysis, integration, or feedback control. For instance, modeling and analysis of a driveline dynamometer, development of a security system for Mr. Burns from the Simpsons [17], and correction of incorrect PID gains for a chemical process controller. Starting in Fall 2014, a single module spanning 12 weeks with 3 large deliverables covering modeling and analysis of a dynamic system, sensor and actuator design and integration, and feedback control was deployed $[9,10]$.

The Fall 2014 problem, “Wrongful Injury Lawsuit: Who's at Fault?”, provided in Appendix A. Additional detailed instructions were provided to guide student work through the system modeling, analysis, system integration, and feedback control phases. Despite the naming of a specific client and stakeholders, students made little to no effort to connect with the client, consider the economics of the problem, or think about the bigger picture. Aside from requesting specific details about the manufacturing plant layout, students were generally content to ignore the problem statement and consider only the generic gantry crane. 
Building on the existing PBL structure, project descriptions and staging in Fall 2015 and Fall 2016 years were modified to explicitly facilitate growth in the entrepreneurial mindset. As in Fall 2014, the problem descriptions provided to students in Fall 2015 and Fall 2016 identified real-world problems: water purification in Fall 2015 and widespread application of selective laser sintering (SLS) in Fall 2016. Unlike previous iterations, these problems were posed to students from a designated customer: the Dr. Mynderse World Improvement Foundation (DMWIF). While admittedly silly, the DMWIF provided a customer face and allowed students to ask technical questions of the instructor as well as customer preference questions of the DMWIF representative. Problem descriptions are provided in the Appendices B and C.

Like previous projects, the work was staged with specified deliverables. In the first stage, prior to modeling, analysis, or design, students were tasked with thinking critically about the market served by the product in question including stakeholders, funding mechanisms, and available resources. The Stage 1 task list for Fall 2016 is provided below.

\section{Stage 1}

- Describe the operation and major elements of a selective laser sintering system.

- Identify all stakeholders.

- Interview stakeholders to determine target applications and appropriate cost target.

- Identify target materials for use in the prototype system.

- Identify all safety concerns for the prototype system.

These market parameters framed the following technical stages. For example, stakeholders interviewed in the SLS project included tech shop owners, machine shop employees, and fellow students. This provided the student teams with information about desired part sizing and materials, training requirements, and overall cost. The concept of "stakeholders" was new to BSME students. To address questions about who qualified as a stakeholder and who did not, video lectures from a Construction Project Management course taught by Prof. John Tocco were provided to students. The second major challenge in this stage was actually conducting an interview; students questioned whether or not they were really meant to go interview someone (they were).

In Stage 2, the results of Stage 1 informed the selection of an appropriate laser and manufacturing tolerances which then informed the design of a motion system, as shown below for Fall 2016. At this stage, the course objective of modeling dynamic systems is addressed in the context of a realworld system. 


\section{Stage 2}

- Having completed Stage 1, it is assumed that your design team understands the SLS process and has determined a target application, price point, and materials. Provide a short recap of these elements.

- Identify a laser capable of sintering your target materials. This should include laser type, size, focal length (including lenses if needed), cost, and any other necessary parameters. Note: this is not an optics course.

- Combining your laser spot size, application, and materials, determine appropriate tolerances for SLS manufactured parts.

- Design a motion system to accurately direct the laser beam onto the powder bed within your stated tolerances and within the target print time. The Foundation has determined that the motion system should use DC motors for actuation. Deliverables should include sketches (CAD optional) and written description. Note: this is not a machine design course; for this stage it is sufficient to leave sizing parameters as undetermined constants. (They will be needed in the next stage.)

- Model your designed motion system. Identify inputs and outputs, constants which depend upon the design, and disturbance inputs. Deliverables should include derivation of model, MATLAB and/or Simulink code, and written description. Note: this is a mechatronics course.

The design of the motion system was relatively straightforward, given the number of commercial 3D printers available as models. Similarly, modeling of the designed system directly applied class principles and did not cause unnecessary difficulty. The challenge in this stage was in the identification of design targets: laser, material, application, and tolerances. In particular, students determined that the laser selection and material cost were significant based on pricing constraints expressed by stakeholders.

Following the submission of Stage 2, student teams were provided another team's Stage 1 and Stage 2 deliverables along with a rubric. Each student conducted a peer review and the time was sufficient to allow each student to review deliverables from two other teams. Student-completed rubrics were provided to the team being scored for use in Stage 3. Student-completed rubrics were not collected by the instructor or incorporated into grading. No assessment on the benefits of peer review was performed. However, students indicated that they valued the activity.

Analysis of the dynamic system was treated in Stage 3, along with editing based on the results of the peer review session. Time response and frequency response of a dynamic system were technical learning objectives for the course. The Stage 3 description for Fall 2016 is shown below. Following submission, Stage 3 deliverables were scored for technical criteria with a rubric similar to that from the peer review. Several dimensions were added to evaluate Stage 3 in addition to those addressed in Stages 1 and 2. 


\section{Stage 3}

- Having completed peer review on Stage 1 and Stage 2, make edits as needed. Combine Stage 1 and Stage 2 with the following requirements for Stage 3 to make a single submission.

- Based on peer review, edit your previously developed model of your laser motion system as needed.

- Choose appropriate values for design parameters within your laser motion system. Do the laser system and laser motion system meet your selected target cost? You may neglect the costs associated with powder, the powder distribution system, and structural elements.

- Simulate the time response and frequency response of your laser motion system device for appropriate input types and ranges. Does it meet the needs of your selected target application?

System integration was addressed in Stage 4, again including explicitly the economics of the problem. In this case, energy consumption and annual operating costs were required. As in Stages 2 and 3, the technical content of Stage 4 (sensors, actuators, microcontrollers) addresses technical learning objectives for the overall course. The Stage 4 description for Fall 2016 is shown below.

\section{Stage 4}

- It is assumed that the laser beam motion will be improved using a feedback controller with two zeros and two poles. Note: you may assume that the feedback controller will require a sample rate 20 times the highest frequency dynamic associated with the control loop. Coordination of the proposed SLS system, including commanded locations for the laser beam position, motion of the powder distribution system, and powder bed vertical position, will be implemented using a finite state machine. Note: you are not required to design the feedback controller or state machine.

- Select appropriate sensors and actuators to implement the proposed system. These may include position/velocity/acceleration sensors, temperature sensors, motors, linear actuators, and many others. Note: accuracy, speed, and cost all matter!

- Select an appropriate microcontroller(s) to implement the proposed SLS system. If necessary, design appropriate interfaces between sensors and actuators and the microcontroller(s). Note: while useful in class, the 


\section{Arduino Uno is likely not sufficiently powerful to implement feedback control.}

- Determine the total power needs for your proposed SLS system at idle and during operation. Select an appropriate power supply for your proposed SLS system.

- Determine the annual operating costs of your proposed SLS system.

Deliverables were evaluated with a rubric including dimensions for sensor selection, sensor integration, actuator selection, and actuator integration. Students selected a variety of sensors and actuators. As with the design targets, the wide-open nature of the problem lead to initial frustration and much searching on the Internet. Results for sensor and actuator integration were very poor with little to not thought given to needed ADC, DAC, or filters. The inclusion of microprocessor specifics was a mistake due to the significant challenge that it posed to the students. While the concepts are details are relevant and important to the project, the time could have been better spent increasing depth on sensors and actuators.

The final concept to be covered was feedback control. Rather than ask students to build their proposed laser positioning system and then apply feedback control, a simple servo motor experiment was substituted. Stage 5 provided a step-by-step guide to collecting data for system identification and implementing a designed controller in transfer function form. MATLAB was used for data analysis and controller design and National Instruments cRIO hardware was used for controller implementation. This proved to be a struggle for students due to the available time. Data collection and system identification, controller design, and controller implementation and validation could have each taken a full lab period. Unfortunately, only two lab periods were allocated. Future project iterations will budget additional time for this stage.

\section{Assessment of Entrepreneurial Mindset Example Behaviors}

Student surveys were used to qualitatively assess the effectiveness of the EML experience in teaching mechatronics and instilling an entrepreneurial mindset. To limit the length of the survey, only a few dimensions of the entrepreneurial mindset were included. For initial implementation, the more accessible and relevant dimensions were addressed. Future work will focus on the more complex dimensions and identify specific course modifications to encourage those behaviors. Student responses to general questions regarding the EML experience are shown in Table 2. From the general questions, students mostly identified their projects as accomplishing the required task (mean 3.89) and being successful (mean 3.92). However, student responses to questions about being motivated by the real-world and open-ended application were more varied. 
Table 2. All students' ratings $(\mathrm{N}=48)$ of general statements after completion of the EML design experience. Using a scale of 1 to 5, 1 indicates "strongly disagree" and 5 indicates "strongly agree."

\begin{tabular}{|c|c|c|}
\hline 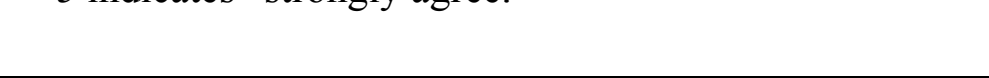 & Mean & St. dev. \\
\hline My project accomplished the required task & 3.89 & 0.89 \\
\hline I consider the results of my project successful & 3.92 & 0.82 \\
\hline I found my work on the project to be satisfying & 3.63 & 1.02 \\
\hline $\begin{array}{l}\text { The real-world application of the project motivated me to } \\
\text { do my best work }\end{array}$ & 3.65 & 1.06 \\
\hline $\begin{array}{l}\text { The open-ended nature of the project motivated me to do } \\
\text { my best work. }\end{array}$ & 3.42 & 1.15 \\
\hline
\end{tabular}

Student responses to questions regarding demonstration of entrepreneurial mindset example behaviors are shown in Table 3. Given that the posed problems were new and complex concepts for students, it came as no surprise that students identified "integrate information from many sources to gain insight" (mean 4.17), "apply systems thinking to complex problems" (mean 4.02), and "apply creative thinking to ambiguous problems" (mean 3.98) as the most frequently demonstrated entrepreneurial mindset example behaviors. Based on the inclusion of the DMWIF as a clear customer requesting expected operating costs, it is also not surprising that students identified "convey engineering solutions in economic terms" (mean 3.70) as being demonstrated between "sometimes" and "often". It was surprising that for a project with multiple deliverables the behavior "substantiate claims with data and facts" (mean 3.87) did not rank higher. Taken as a whole, students self reported demonstrating all entrepreneurial mindset example behaviors at least "sometimes".

Table 3. All students' ratings ( $\mathrm{N}=48)$ of EML-specific statements after completion of the EML design experience. Using a scale of 1 to 5, 1 indicates "none at all" and 5 indicates "throughout most of the project."

\begin{tabular}{|c|c|c|}
\hline 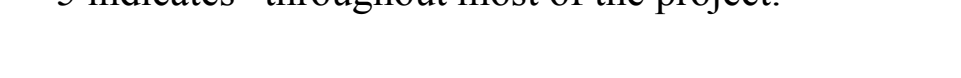 & Mean & St. dev. \\
\hline \multicolumn{3}{|l|}{ During the course of this project, to what extent did you: } \\
\hline Integrate information from many sources to gain insight & 4.17 & 0.78 \\
\hline Assess and manage risk & 3.18 & 1.01 \\
\hline Persist through failure & 3.79 & 1.05 \\
\hline Apply creative thinking to ambiguous problems & 3.98 & 0.79 \\
\hline Apply systems thinking to complex problems & 4.02 & 0.81 \\
\hline Convey engineering solutions in economic terms & 3.70 & 0.86 \\
\hline Substantiate claims with data and facts & 3.87 & 0.92 \\
\hline
\end{tabular}




\section{Conclusion}

A junior/senior level mechatronics course within the undergraduate mechanical engineering program was modified to include entrepreneurially minded learning content in existing problembased learning activities. The real-world projects incorporated modeling and analysis of dynamic systems, selection and integration of sensors and actuators, and feedback control. This study assessed the course modifications based on student behaviors corresponding to an entrepreneurial mindset as defined by the KEEN framework. Student surveys indicate that the students demonstrated the tested entrepreneurial mindset example behaviors at least "sometimes" and up to "often". Further work is needed to test all example behaviors within the KEEN entrepreneurial mindset framework.

\section{References}

[1] D. Carpenter, K. Hayes, C. Ward and A. L. Gerhart, "Assessment and Evaluation of a Comprehensive Course Modification Plan," The Journal of Engineering Entrepreneurship, vol. 2, no. 2, 2011.

[2] A. L. Gerhart and D. D. Carpenter, "Campus-wide Course Modification Program to Implement Active \& Collaborative Learning and Problem-based Learning to Address the Entrepreneurial Mindset," in Proc. 2013 ASEE Annual Conference and Exposition, Atlanta, GA, 2013.

[3] A. L. Gerhart and D. E. Melton, "Entrepreneurially Minded Learning: Incorporating Stakeholders, Discovery, Opportunity Identification, and Value Creation into Problem-Based Learning Modules with Examples and Assessment Specific to Fluid Mechanics," in Proc. 2016 ASEE Annual Conference \& Exposition, 2016.

[4] K. A. Smith, S. D. Sheppard, D. W. Johnson and R. T. Johnson, "Pedagogies of Engagement: Classroom-Based Practices," Journal of Engineering Education, vol. 94, no. 1, pp. 87-101, 2005.

[5] M. Prince, "Does Active Learning Work? A Review of the Research," Journal of Engineering Education, vol. 93, no. 3, pp. 223-331, 2004.

[6] A. L. Gerhart and D. E. Melton, "Entrepreneurially Minded Learning: Incorporating Stakeholders, Discovery, Opportunity Identification, and Value Creation into Problem-Based Learning Modules with Examples and Assessment Specific to Fluid Mechanics," in Proc. 2016 ASEE Annual Conference \& Exposition, 2016.

[7] A. L. Gerhart and R. W. Fletcher, "Project-Based Learning and Design Experiences in Introduction to Engineering Courses: Assessing an Incremental Introduction of Engineering Skills," in Proc. 2011 ASEE Annual Conference \& Exposition, 2011.

[8] A. L. Gerhart, D. D. Carpenter, R. W. Fletcher and E. G. Meyer, "Combining Discipline-specific Introduction to Engineering Courses into a Single Multidiscipline Course to Foster the Entrepreneurial Mindset with Entrepreneurially Minded Learning," in Proc. 2014 ASEE Annual Conference \& Exposition, 2014.

[9] J. A. Mynderse, A. L. Gerhart, L. Liu and S. Arslan, "Multi-course Problem-based Learning Module Spanning Across the Junior and Senior Mechanical Engineering Curriculum: Mechatronics, Fluid Mechanic, and Heat Transfer," in Proc. 2015 ASEE Annual Conference \& Exposition, Seattle, 2015.

[10] L. Liu, J. A. Mynderse, A. L. Gerhart and S. Arslan, "Fostering the Entrepreneurial Mindset in the Junior and Senior Mechanical Engineering Curriculum with a Multi-Course Problem-based Learning Experience," in Proc. 45th ASEE/IEEE Frontiers in Education Conference, 2015.

[11] J. A. Mynderse and J. N. Shelton, "Implementing Problem-Based Learning in a Senior/Graduate Mechatronics Course," in Proc. 2014 ASEE Annual Conference and Exposition, Indianapolis, 2014.

[12] J. A. Mynderse and J. Shelton, "Assessment of an Improved Problem-Based Learning Implementation in a Senior/Graduate Mechatronic Design Course," in Proc. 2015 ASEE Annual Conference and Exposition, Seattle, 2015.

[13] Kern Entrepreneurial Engineering Network, "Entrepreneurial Mindset 101," [Online]. Available: http://engineeringunleashed.com/keen/em101/. 
[14] K. Craig, "Is anything really new in mechatronics education?," IEEE Robotics \& Automation Magazine, vol. 8, no. 2, pp. 12-19, 2001.

[15] L. W. Anderson and D. R. Krathwohl, Eds., A Taxonomy for Learning, Teaching, and Assessing: A Revision of Bloom's Taxonomy of Educational Objectives, New York: Longman, 2001.

[16] J. V. Canino, "Comparing Student Performance in Thermodynamics Using the Flipped Classroom and ThinkPair-Share Pedagogies," in Proc. 2015 ASEE Annual Conference \& Exposition, Seattle, Washington, 2015.

[17] J. A. Mynderse, "Protecting/Stealing the Trillion-Dollar Bill," PBL Clearinghouse, [Online]. Available: http://www1.udel.edu/pblc/. 


\section{Appendix A - Fall 2014 Problem Description}

\section{Wrongful Injury Lawsuit: Who's at Fault?}

The M1A2 Abrams tank is an American generation main battle tank. The M1A2 weighs in at 68 tons yet manages to reach speed of $42 \mathrm{mph}$ while firing the $120 \mathrm{~mm}$ cannon reliably, due to a stabilized gun mount.

The Joint Systems Manufacturing Center

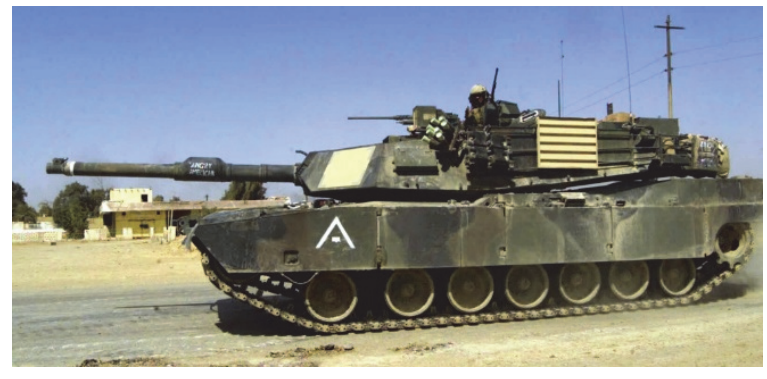

thirda top (JSMC), operated by General Dynamics Land Systems, is a government-owned, contractoroperated facility which makes armored vehicles such as the M1A2. During the fabrication process, workers weld together thick steel plates to form the vehicle hull, turret, and side walls.

The JSMC uses an overhead gantry crane system to move extremely heavy armor sections from the staging area into a work cell and then to move completed turrets, hulls, and sidewalls from the work cells to an assembly area. The crane is operated by a trained worker who uses a handheld pendant to control motion of the load in six axes.

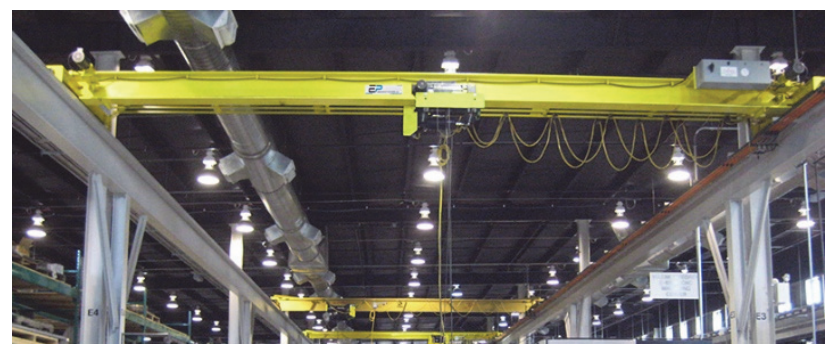

In 2010 a welder was injured when a suspended load knocked over a stack of armor steel. The employee filed a wrongful injury lawsuit claiming that the employer, GDLS, failed to properly train the crane operator. Your team has been retained by the law firm of Stone, McCoy, and Cutter, acting as counsel to the plaintiff, to investigate the incident.

You are tasked with addressing the following questions:

1. Under what circumstances could a suspended load swing beyond the intended pathway?

2. Could any single fault in the crane control systems have caused the injury?

3. Can the faulty crane operation be demonstrated in a courtroom in a dramatic fashion? 


\section{Appendix B - Fall 2015 Problem Description}

\section{Water Purification on the Cheap}

According to UN-Water, 748 million people do not have access to an improved source of drinking water and 2.5 billion do not use an improved sanitation facility. Diarrhea is the $4^{\text {th }}$ leading cause of child death, largely from water-related disease. Access to clean water could save over 600,000 children each year.

Many areas of the world are affected as a result of underdevelopment, war, and migration. Palestinian settlements in the Gaza Strip and West Bank suffer severe

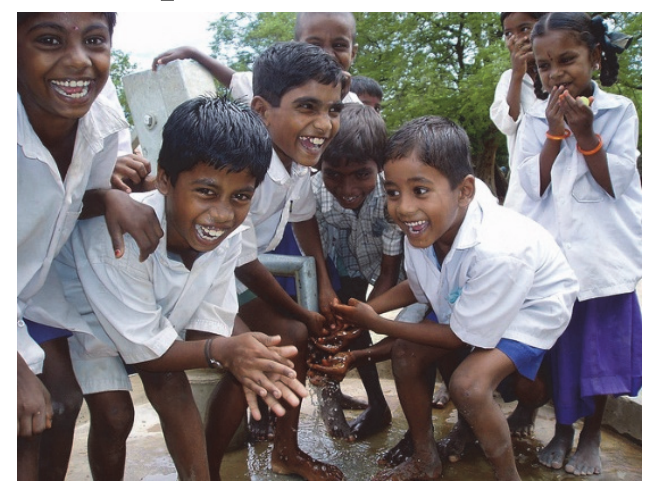
water shortages. A 2012 survey by the Palestinian Water Authority identified only $21.5 \%$ of wells as meeting WHO standards for water purity. As a result of the Syrian civil war areas of the

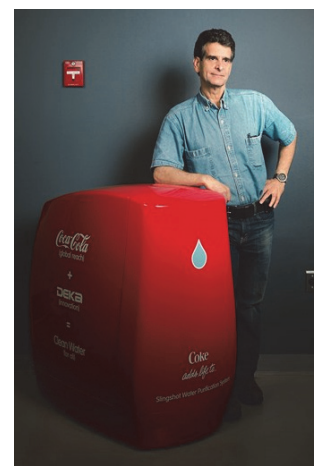
city of Aleppo were without reliable access to water. UNICEF reported that there were a record 1,700 Hepatitis A cases reported in one week in February 2015 and 3,000 children were reported with mild cases of diarrhea in the first three weeks of July 2015.

Several options have been proposed for low-cost water purification. The Lifestraw is a cigar-shaped tube which filters out potential pathogens, the Cycloclean is a bicycle powered water filter, the Solar Ball is a solarpowered evaporative device, and the Slingshot Water Purifier is an evaporative water purification device invented by Dean Kamen.

The Dr. Mynderse World Improvement Foundation is now accepting proposals for low-cost water purification projects in needy areas world wide. Your team will be preparing a proposal for both a water purification device and test stand for validation. Your device must meet the following guidelines:

- The device should be targeted to a specific location and identify an appropriate cost point, so as to maximize the benefit of funding provided by the Foundation.

- The device should include water purification and storage sufficient to meet the needs of a small community.

- The device should be powered only by regionally appropriate fuel sources and not require consumable components which are not regionally available.

- The test stand should be capable of measuring input energy and output water purity at a range of throughputs to validate the usage of the device.

During development of the proposals, teams will be required to provide periodic updates to the Foundation. Following review of the proposals, one or more may be selected for additional development. 


\section{Appendix C - Fall 2016 Problem Description}

\section{Personal Manufacturing for Everyone}

The Dr. Mynderse World Improvement Foundation was founded with the mission to "improve the welfare of all humankind through mechatronics". The Board of Directors believes that additive manufacturing can provide immense benefits by providing individualized parts on-demand. In contrast to fused deposition methods, selective laser sintering holds great promise for working with a variety of materials including metals.

Large-scale laser sintering systems are commercially available, but the cost is high: approximately $\$ 1 \mathrm{M}$ per machine. Newer

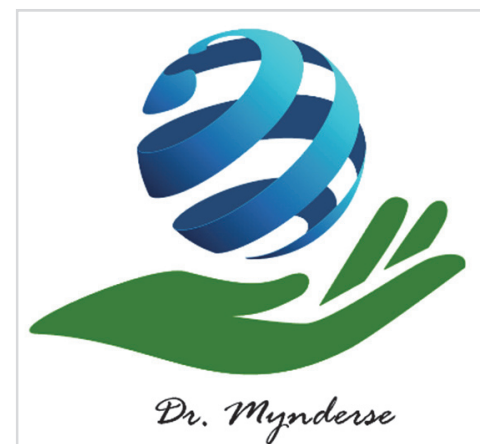

World lmprovement Foundation laser sintering devices are more similar in price-point to common fused deposition 3D printers but are still not as ubiquitous and easy to use. The Dr. Mynderse World Improvement Foundation envisions a world where those in need can visit a library or makerspace and print functional replacement parts for items as varied as dental implants, prosthetics, home appliances, and sports equipment.
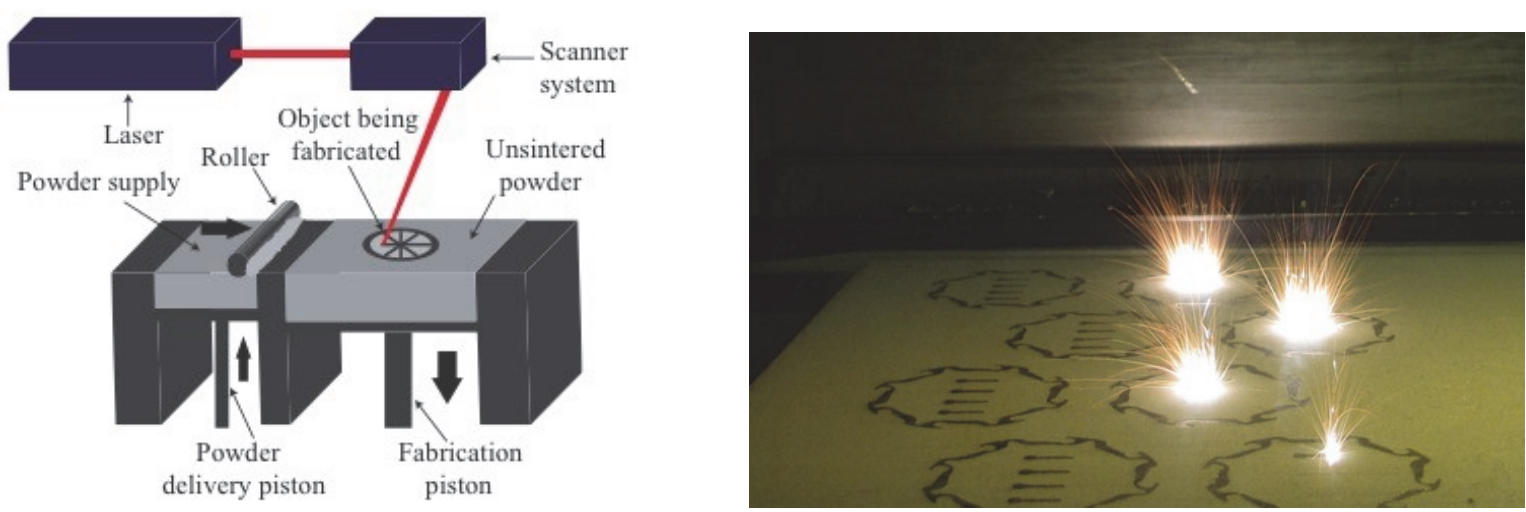

The Dr. Mynderse World Improvement Foundation is now accepting proposals for low-cost personal manufacturing systems based on selective laser sintering for use worldwide. Note that low-cost does not mean cheap! Your team will be preparing a proposal for funding to develop a working prototype system. Your device must meet the following guidelines:

- $\quad$ The device should print as fast as existing 3D printers.

- The device should be safe to use in a public space, such as a library.

- The low-cost target should include initial part costs, installation costs, and per year usage costs including consumables and energy.

During development of the proposals, teams will be required to provide periodic updates to the Foundation. Following review of the proposals, one or more teams may be selected for additional development. 